\title{
Antecedents Of Successful Web Based Communities For Disabled Citizens
}

\author{
James Lawler, (E-mail: jlawler@pace.edu), Pace University
}

\begin{abstract}
In this period of constrained economic conditions, this study initiates an analysis of the critical success factors in the implementation of World Wide Web-based communities in the non-profit sector, focusing on communities of challenged citizens who have mental health conditions in the City of New York. Non-profit organizations in New York depend ever more upon the technology of the Web to help disabled members in the city, as the disruption from the September 11 disaster continues to impact social services. Though investment in technology is limited in the non-profit sector, the preliminary analysis of this study imputes that implementation of community networks that service rehabilitating members of society is facilitated by distinct enabling success factors of cohesion, effectiveness, help, language, relationship and self-regulation in the innovation of the supporting Web sites. The analysis contributes insight into the dynamics of communities on the Web that is applicable in an international context. This study furnishes a new framework to research Web-based communities in the non-profit sector.
\end{abstract}

\section{Background}

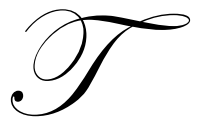

he Internet is a critical component in the business of the corporate profit sector. Commerce and informational content in the marketing and sales of products are characteristics effected on the Web sites of corporate organizations. Customization in the context of interactions and services is enabled in transactions on the sites. Communication and connection are introduced in chat, e-mail, help features, instant messaging and message board functionality on the Web sites, that facilitates a community of consumers. Those that manage in the corporate profit sector are cognizant of the importance of technology, as they are defined as early adopters or early majority innovators on the Web (Rogers, 1983).

Those in the non-profit sector are conscious of the importance of the Web, but, constrained more by financial limitations than the profit sector (Atkinson \& Court, 1998), are frequently defined as late majority or laggards in innovation on the Web (Rogers \& Albritton, 1995 \& Wagner, 1999). Though composites of content, context, communication, community, connection, customization and commerce characterize sites in non-profit organizations, the concern of this study is in the criticality of community in the success of non-profit sites. Community is defined in the study in the following:

A feeling of membership in a group along with a strong sense of involvement and shared common interests ... [that] creates strong, lasting relationships ... through an engaged and extended exchange of views focused on ... [the] shared interests, ... [that] contains individual involvement, [and that] can help encourage [disabled citizens] to return to a [non-profit] Web site.

This definition is important in the concept of a Web based community, as an expanding social network of sites on the Web. Such expansion significantly empowers disabled citizen members served by sites in the non-profit sector.

The empowerment of disabled citizens in a Web based community is enabled in the design of non-profit organizational sites that are considerate of the myriad needs of the citizens. Factors of design include guidelines of the World Wide Web Consortium (W3C) and the international Web Accessibility Initiative (WAI) that inform 
organizations in principles of content and navigational usability of sites accessed by disabled members of a community (Chisholm, Vanderheiden \& Jacobs, 1999 \& Randall, 1999). Tim Berners-Lee, inventor of the World Wide Web, indicated that accessibility irrespective of disability is essential to Web sites, as the strength of the Web is in its universality. The Center for Universal Design at North Carolina State University instructs organizations in design principles in adaptive hardware and software site technologies (Connell, Jones, Mace, Mueller, Mullick, Ostroff, Sanford, Steinfeld, Story \& Vanderheiden, 1997). Studies in the literature have analyzed fundamental factors in the design of successful Web sites for disabled citizens (Kautznar, 1998). Few of the studies have analyzed the factors in the successful implementation of a Web-based community for rehabilitating disabled citizens, who have mental health conditions, the emphasis of this study.

\section{Introduction}

This study analyzes a Web-based community of a Community Access non-profit organization in the city of New York. The charter of the organization is to help disabled but rehabilitating citizens, who have mental health conditions, in civic and commercial interactions and social services, which have been dislocated and disrupted by the September 11 World Trade Center disaster and subsequent urban renewal. These citizens actually include prolific artists in the city and the larger state of New York that need help in displaying their art in community forums. Due to financial limitations, the affiliate agency of the non-profit organization, Club Access, approached Pace University, also in the city, to assist the organization in the implementation of community Web sites to help the dexterous rehabilitating citizens. Funded by a grant, these sites were implemented in a project in a civic engagement course entitled Web Design for Non-Profit Organizations, by students in the School of Computer Science and Information Systems of the university.

The implementation intent of the non-profit organization was only Club Access sites, illustrated in Figure 1 , to help the rehabilitating artists in displaying their art and in interacting and sharing with the agency organization and artists in New York City on the Web.

Figure 1: Club Access Community Web Site

\begin{tabular}{|c|c|c|c|c|}
\hline $\begin{array}{l}\text { About } \\
\text { Us }\end{array}$ & $\begin{array}{l}\text { Becoming a } \\
\text { Club Member }\end{array}$ & $\begin{array}{c}\text { Art } \\
\text { Gallery }\end{array}$ & $\begin{array}{l}\text { Club } \\
\text { News }\end{array}$ & $\begin{array}{l}\text { Contact } \\
\text { Us }\end{array}$ \\
\hline Mission & \multirow{2}{*}{$\begin{array}{l}\text { A Day in the Life } \\
\text { of a Member } \\
\text { Virtual Tour }\end{array}$} & Artists & \multirow[t]{2}{*}{ Calendar of Events } & Bulletin Board \\
\hline Board of Directors & & Artist Biographies & & Club Chat \\
\hline History & $\begin{array}{l}\text { Steps to } \\
\text { Membership }\end{array}$ & Art Portfolios & $\begin{array}{l}\text { Clubhouse } \\
\text { Newsletter }\end{array}$ & Discussion Forums \\
\hline \multirow[t]{2}{*}{ Locations in City } & $\begin{array}{l}\text { Frequently Asked } \\
\text { Questions }\end{array}$ & Art Portfolio Links & $\begin{array}{l}\text { Neighborhood } \\
\text { Trips }\end{array}$ & E-Mail Links \\
\hline & & Art Shows & & Word of Mouth \\
\hline
\end{tabular}

However, the project is being implemented in the conception of a Web based community, illustrated in Figure 2 , that is effecting a social network that includes academic non-profit, community organization non-profit, and corporate and public profit sector sites in New York, the United States and internationally, that will be $24 \times 7$ and multilingual. In fact, the community is enabling not only art display and artist interaction, but also entrepreneurial marketing and sales of the art to gallery exhibitors and owners, partnership on art sites, such as shutterfly.com, citizen donor solicitation, and general public support on the Web. The implementation further includes health center and medical rehabilitation sites in the city and state of New York. The expansion of the Club Access sites to other 
community sites in a Web-based community is helping the rehabilitating artist citizens in downtown New York, improving the sense of community, and is a successful implementation.

The focus of analysis in the implementation is centered on the site factors enabling engagement success of this Web-based community. Rayport and Jaworski define success factors in a design methodology that introduces cohesion, effectiveness, help, language, relationship and self-regulation (Rayport \& Jaworski, 2002) in the functionality of a community Web site.

Figure 2: Virtual Web Based Community Network

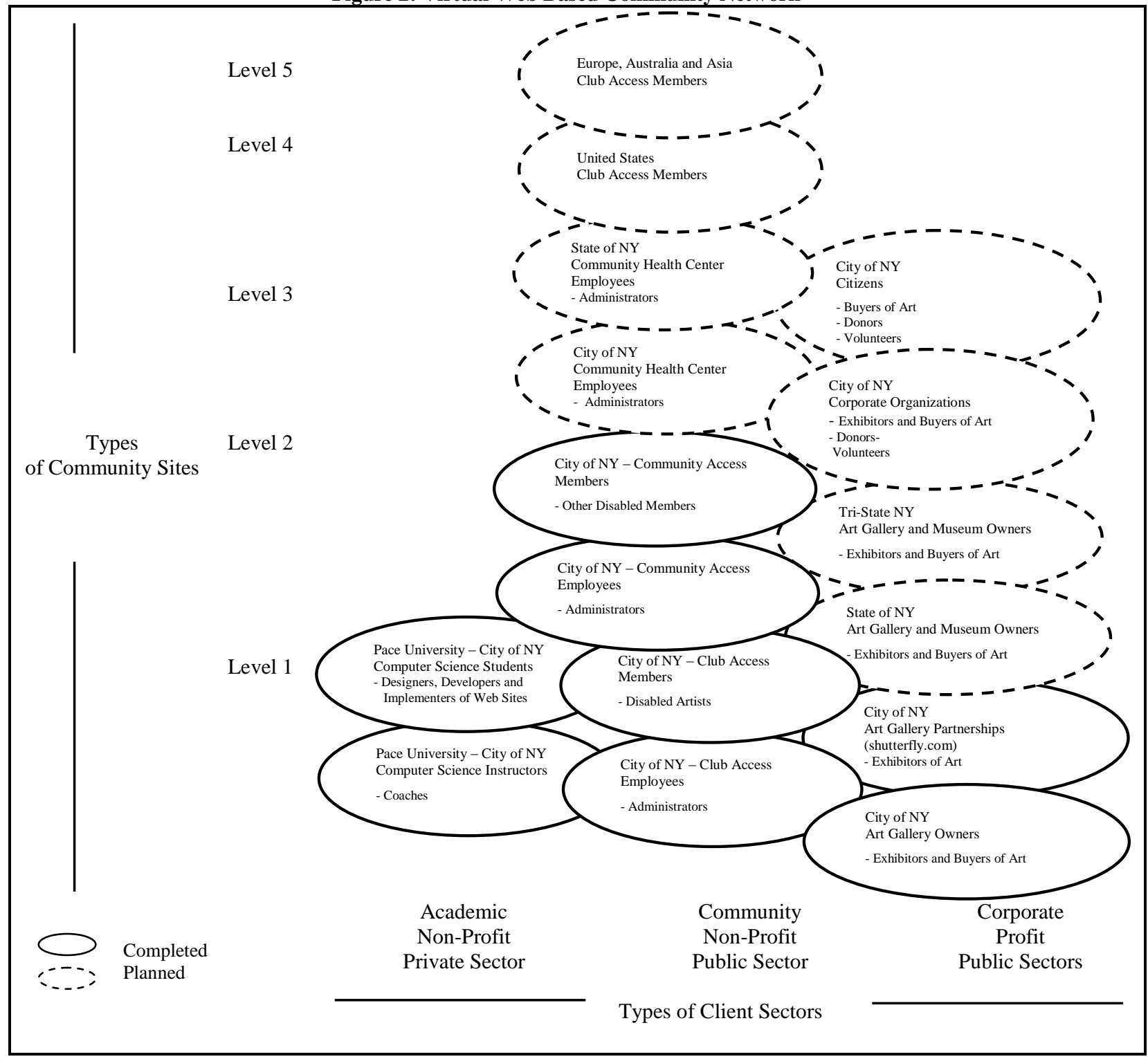


The factors are defined in the following:

- $\quad$ cohesion, element of design from which members have a feeling of belonging in the community;

- $\quad$ effectiveness, element from which members have a feeling of impact from the community;

- $\quad h e l p$, element from which members have help from the community;

- language, element from which members have a forum for specialized languages in the community;

- $\quad$ relationship, element from which members have interaction and friendship in the community; and

- $\quad$ self-regulation, element from which members regulate their interactions on the community site.

These factors are imputed to facilitate fulfillment, inclusion, influence and emotional experience sharing (Rayport \& Jaworski, 2002) in a successful Web-based community. Though the project in the study applied these factors in the implementation of initial community, its extension as a successful model to other Web-based communities in the non-profit sector is not substantiated empirically by Rayport and Jaworski or theorists.

\section{Focus of Study}

The focus of this study, illustrated in Figure 3, is to analyze in survey and regression the significance of the critical factors of engagement success in a Web-based community for challenged but rehabilitating citizens, applying the Rayport and Jaworski factors of cohesion, effectiveness, help, language, relationship and selfregulation to Club Access as a case study. The study demonstrates the importance of these factors in a successful social Web-based community for disabled but dexterous rehabilitating members, who have mental health conditions, albeit implemented adaptive technologies. No academic studies known to the author have analyzed in this manner the non-profit sector of Web-based communities that help rehabilitating citizens, and the study will benefit educators and researchers in this sector.

Figure 3: Club Access Web Based Community Design

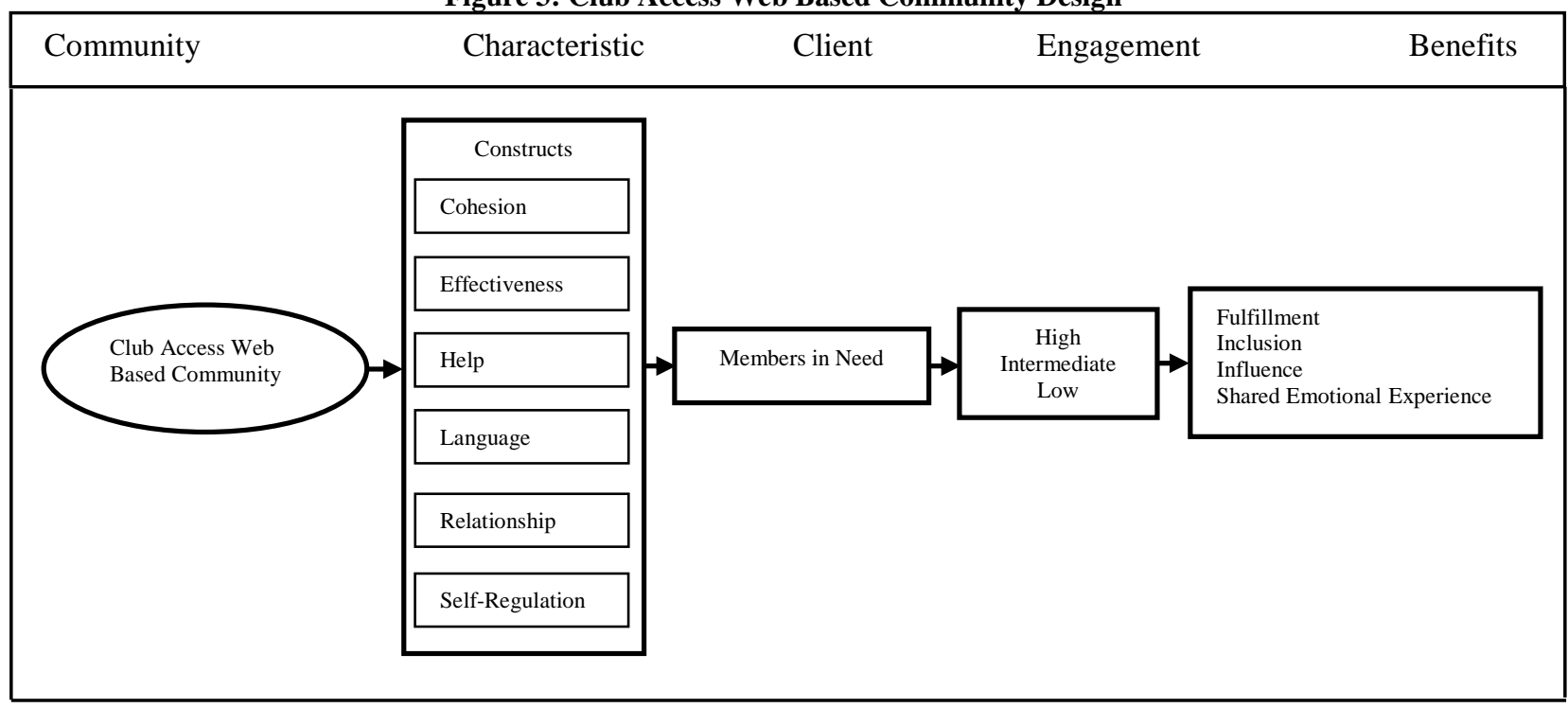

\section{Research Methodology}

The research methodology of this preliminary study analyzed the Web-based community of Club Access in New York, in three stages of analysis. 
In stage 1, a controlled but diverse sample of 300 members of Club Access in the city was surveyed by questionnaire by the author. The multi-page questionnaire, which consisted of 24 questions, surveyed the members anonymously in the importance of the Rayport and Jaworski factors of cohesion, effectiveness, help, language, relationship and self-regulation employed in the Web-based community, in a three point high, intermediate or low Likert scale. From a preliminary analysis of the member rating results of the survey, hypotheses are introduced in the current study. university.)

(The questionnaire was pre-tested for reliability by students in a marketing research program of the

In stage 2, the survey is being expanded to include members throughout tri-state New York and the United States, and the hypotheses will be enhanced from the rating results of the expanded survey. In stage 3 of this advanced study, the hypotheses will be analyzed through SPSS statistical interpretation, with the final study completed by the author.

\section{Analysis of Web-Based Community}

From stage 1 of the study, a summary of the analysis indicates that most of the member sample indicated high to intermediate importance in cohesion (74\% [rank 1]), help (63\% [2]), effectiveness (58\% [3]) and relationship (50\% [4]) factors, but low importance in language (29\% [5]) and self-regulation (26\% [6]) factors, in the engagement of members. The study requires further analysis in stage 2 and 3 to test the following hypotheses implied from the results of stage 1 :

H1. The higher the element of cohesion in the design of a Web-based community for disabled but dexterous members, the higher the engagement;

H2. The higher the element of help in the design of a Web-based community for disabled but dexterous members, the higher the engagement;

H3. The higher the element of effectiveness in the design of a Web-based community for disabled but dexterous members, the higher the engagement;

H4. The higher the element of relationship in the design of a Web-based community for disabled but dexterous members, the higher the engagement; and

H5. The lower the elements of language and self-regulation, the higher the importance of cohesion, help, effectiveness and relationship in engagement of members.

Though the results of the study will not be final until completion of stage 3 in 2004, the preliminary results are helpful in initially analyzing a non-profit Web-based community.

\section{Implications of Study}

The preliminary non-empirical findings of this study imply the design importance of the Rayport and Jaworski cohesion, effectiveness, help, language, relationship and self-regulation factors, in the heightened engagement of dexterous rehabilitating disabled members in a non-profit Web-based community. Though the nonprofit sector is perceived to be a laggard in the funding of community enabling technologies, the innovation in Web communities in the profit sector illustrates features of interactivity that is feasible to implement in the non-profit sector with limited investment. Features of chat, e-mail, help, instant messaging and message board functionality that are customized to the felt needs of members facilitate the community engagement factors. Such features personalized to citizen donors further facilitate the factors. The engagement factors in a Web-based community are impacted not only by their design, but also by the evolution of technologies on the Web.

The findings of the study concurrently indicate the importance of member perception in a Web-based community. Studies in the literature posit that engagement in innovation in a social system is influenced by how its members perceive the performance and benefit of innovation. From stage 1 of this study, the members of Club Access clearly perceive benefits in the factors of cohesion, effectiveness, help, language, relationship and self- 
regulation, enabled in the subjective and objective design of the art galleries, links and portfolios, and enhanced in the seriousness of the shows on the sites. Members of a community are noted in the literature to have a higher perception of benefit in a Web-based community than non-members. These findings in the importance of perception may be helpful in studying how fast the non-profit sector may implement technologies in a Web-based community.

Other findings of the initial study confirm the benefits of including students in a non-profit Web-based community (Alavi, Wheeler \& Valacich, 1995). The students indicated increased learning not only in the technological context of community Web design, but importantly in the social context of the implemented community sites. Though the intent of the Web Design for Non-Profit Organizations course was civic engagement during the duration of the course, the interaction of students and teachers continues with the rehabilitating members, in an expanding and living Web-based community. Employees and managers of the non-profit organization desire further interaction with the university. In essence, the university gains immediate benefits in improved partnership with non-profit civic organizations, through a Web-based community.

\section{Conclusion}

Constrained by financial limitations, the non-profit sector is innovating slowly in the implementation of Web-based communities that help challenged but rehabilitating members of society, who have mental health conditions. The study identified success factors of cohesion, effectiveness, help, language, relationship and selfregulation, which are critical in community sites that help dexterous members. Importance of these factors is indicated in member perception. The onus is on managers in the non-profit sector to ensure successful implementation of these factors on their sites, with the potential help of an academic partnership. Further empirical research is needed in the advanced study, in order to analyze the factors of success in the implementation of Webbased communities in the non-profit sector, not only for the dexterous rehabilitating members, but also for the nondexterous disabled members, and this initial study is facilitating a new framework.

\section{References}

1. Alavi, M., Wheeler, B., \& Valacich, J., (1995) "Using IT to Reengineer Business Education: An Exploratory Investigation of Collaborative Telelearning," Special Issue on IS Curricula and Pedagogy, MIS Quarterly, (19.3), September, 293-313.

2. Atkinson, R.D. \& Court, R.H. (1998) “The New Economy Index: Understanding America's Economic Transformation," The Progressive Policy Institute.

3. Chisholm, W., Vanderheiden, G. \& Jacobs, I. (1999) “Web Content Accessibility Guidelines," World Wide Web Consortium Web Accessibility Initiative.

4. Connell, B.R., Jones, M., Mace, R., Mueller, J., Mullick, A., Ostroff, E., Sanford, J., Steinfeld, E., Story, M. \& Vanderheiden, G. (1997) "The Principles of Universal Design," North Carolina State University, Center for Universal Design, Raleigh, North Carolina.

5. Kautznar, A.M. (1998) "Virtuous Virtual Access: Making Web Pages Accessible to People with Disabilities," The Magazine for Database Professionals, 6 (6), 42-45 and 48-49.

6. Randall, L. (1999) "W3C Proposes Guidelines on Web Accessibility," Newsbytes, March 25.

7. Rayport, Jeffrey F. \& Jaworski, Bernard J. (2002) Introduction to e-Commerce. (McGraw-Hill: New York), 204-206.

8. $\quad$ Rogers, E.M. (1983) "Diffusion of Innovations," The Free Press, Third Edition, New York.

9. Rogers, E.M. \& Albritton, M.M. (1995) "Interactive Communication Technologies in Business Organizations," Journal of Business Communication, 32 (2), 177-195.

10. Wagner, C.K. (1999) "Digital Engine Powers New Economy: Government and Education Are Lagging in the Internet Economy," The Futurist, 33 (14), 20. 